\begin{tabular}{c|c|c}
\hline \hline $\begin{array}{c}\text { Vol. 31(3):239-246 } \\
\text { DOI: } 10.4217 / \text { OPR.2009.31.3.239 }\end{array}$ & Ocean and Polar Research & September 2009 \\
\hline \hline
\end{tabular}

\title{
Article
}

\section{Year-to-year Variability of the Vertical Temperature Structure in the Youngsan Estuary}

\author{
Yang-Ki Cho', Kyeong Sig Lee ${ }^{2^{*}}$, and Kyung-Yang Park ${ }^{3}$ \\ ${ }^{I}$ Department of Oceanography \\ ${ }^{2}$ Interdisciplinary Program of Atmospheric Environmental Sciences \\ Chonnam National University, Gwangju 500-757, Korea \\ ${ }^{3}$ Department of Marine Resources \\ Mokpo National University, Muan 534-729, Korea
}

\begin{abstract}
Long-term observations were conducted between 1997 and 2002 to examine the variability of the vertical temperature structure in the Youngsan Estuary, southwest Korea, in summer. The observed hydrographic data revealed that the temperature minimum layer in the middle depth persisted through the entire summer of 2000 but was rarely observed in other years. The variability in the vertical structure might be affected by the air temperature during the previous winter and the density difference between the open sea and the estuary. In 2000, the air temperature in the previous winter was lowest and the horizontal density difference during summer was largest. The large horizontal density difference probably produced more active driving of warm water along the bottom, which would have intruded into the Youngsan Estuary. Furthermore, the cold previous winter would have provided a better condition for maintaining cold temperatures in the middle water layer for a longer period.
\end{abstract}

Key words : horizontal density difference, temperature minimum layer, vertical temperature structure

\section{Introduction}

Located in southwest Korea, the Youngsan Estuary (YE) is approximately $2 \mathrm{~km}$ wide, $7 \mathrm{~km}$ long, and varies in depth from 5 to $30 \mathrm{~m}$ (Fig. 1). The neighboring sea is shallow, at less than $30 \mathrm{~m}$, with a complicated shoreline and tidal flats. North and south channels connect the YE to the open sea, allowing for exchanges of waters. Tides are semidiurnal, with dominant ebb current. Spring and neap tides are approximately 6 and $3 \mathrm{~m}$, respectively (Lee 1992; Lee 1994; Kang 1999; Byun et al. 2004). Fresh water is mainly supplied to the neighboring sea by the Youngsan River (YR). A $4.3 \mathrm{~km}$ long sea dike was constructed across the YR in February 1981 to reserve fresh water for agricultural use by blocking the saltwater intrusion into the river.

The completion of the sea dike has greatly changed the

\footnotetext{
*Corresponding author. E-mail : mrlee@jeonnam.go.kr
}

estuary environment. The YE acts as an estuary or a bay, depending on the discharge of fresh water from the river. The sea dike has increased the tide amplitude in the YE but has decreased the tidal current speed (Kang 1999; Byun et al. 2004). In turn, the decreased tidal current speed has enhanced water stratification and residence time in the YE during summer (Kang 1999). These environmental variations have led to changes in the ecosystem. Lim and Park (1999) showed that the community and the distribution of the benthos were greatly affected by the change in water quality due to altered physical processes following construction of the sea dike. Strong stratification was found to cause hypoxic conditions in the bottom layer (Lim and Park 1998).

A characteristic multi-layer structure was observed in the estuary in summer, with temperature minima existing in the mid-layer (Cho et al. 2004). Generally, an estuary has a two-layered flow structure composed of a surface layer flowing out and a bottom layer flowing in (Officer 


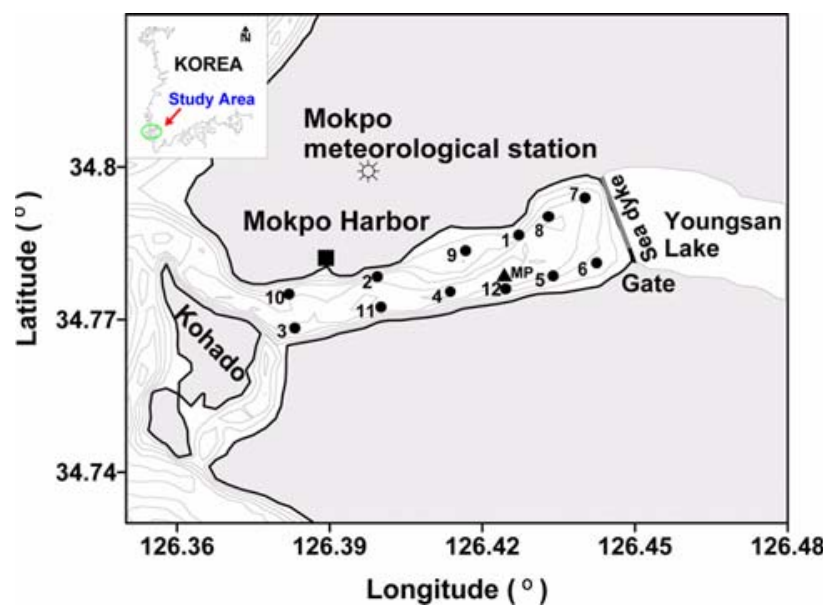

Fig. 1. Topography and observation stations in the Youngsan Estuary. The filled circles and triangle denote the conductivity, temperature, and depth (CTD) observation stations and acoustic Doppler profiler (ADP) mooring station, respectively. The numbers next to the circles represent the station numbers. The interval of the depth contour lines is $5 \mathbf{~ m}$.

1976). However, the construction of a sea dike may change the flow structure as well as hydrographic features (Lewis et al. 1998). Fresh water is discharged intermittently, depending on the operation of the gates of the dike.

In this study, we investigated the variability of the vertical temperature structure by analyzing year-to-year data. In particular, we tested the hypothesis that the multilayered structure observed in 2000 is a consequence of the YE sea dike. The study results will provide valuable information for understanding the dynamics of the multilayered estuary structure.

\section{Observation}

Hydrographic observations were performed for 6 years from July 1997 to September 2002. Conductivity, temperature, and depth (CTD) data were collected roughly twice a week from the surface to the bottom at 12 stations in the YE (Fig. 1). An acoustic Doppler profiler (ADP; Nortek 1.5 MHz) equipped with a temperature sensor was also deployed on the bottom from 1 June to 5 July 2003.

\section{Results}

Variation of air temperature and river water discharge

Meteorological data were collected at Mokpo meteorological station, located about $3 \mathrm{~km}$ from the estuary, between 1997 and 2002. Fig. 2a shows not only the
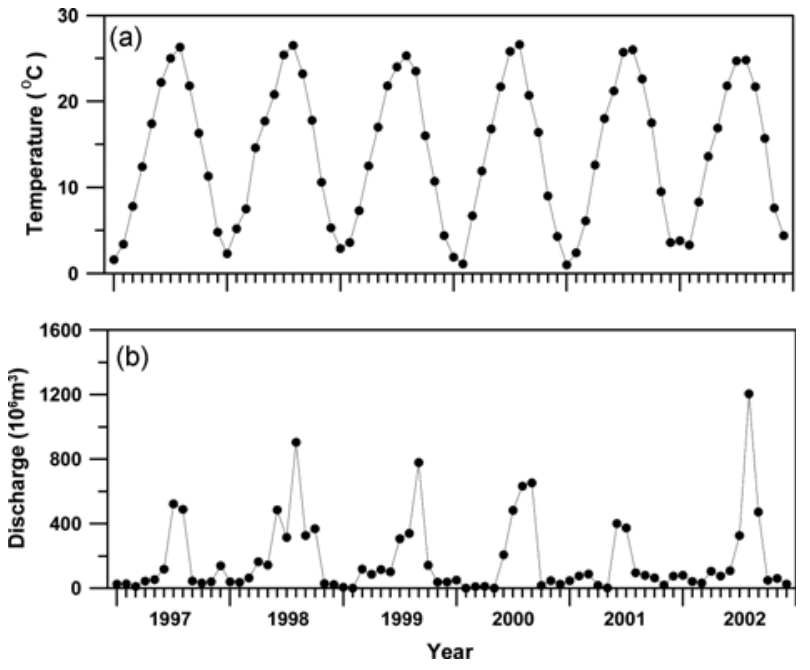

Fig. 2. Interannual variations of the air temperature and volume of monthly river discharges between 1997 and 2002.

seasonal variation but also the year-to-year variation of the air temperature for the study period. In 2000, the summer temperature was highest and the previous winter temperature was lowest, whereas in 2002 the summer temperature was lowest and the previous winter temperature was highest.

To maintain proper water levels in the YR, fresh water is discharged from the river for approximately $2 \mathrm{~h}$ during low tide (Rural Development Corporation of Korea 1999). The annual mean discharge between 1997 and 2002 was $22 \times 10^{8} \mathrm{~m}^{3}$. Fig. $2 \mathrm{~b}$ plots the monthly river discharges for this period. Most discharge was in summer, with the largest volume discharged in August 2002.

\section{Temperature minimum layer}

Vertical temperature sections along the YE on 29 July 1997 and 27 July 2000 clearly show the multi-layer hydrographic structure with a temperature minimum layer in the middle depth (Fig. 3). The multi-layered structure observed during 2000 has been reported in detail by Cho et al. (2004). Warm and less saline water occupied the surface, whereas saline water was present at the bottom. Strong stratification appeared at a depth of $2 \mathrm{~m}$ in both observations. Light water, warmer than $24.0^{\circ} \mathrm{C}$ and with salinity less than $28.0 \mathrm{psu}$, appeared at the surface. The light surface water was diluted fresh water that was discharged from the YR. Surface heating due to increasing solar radiation would have made the surface water lighter during spring and summer, with fresh water inflow and surface heating leading to strong stratification.

The coldest water, less than $23.5^{\circ} \mathrm{C}$, with salinity 

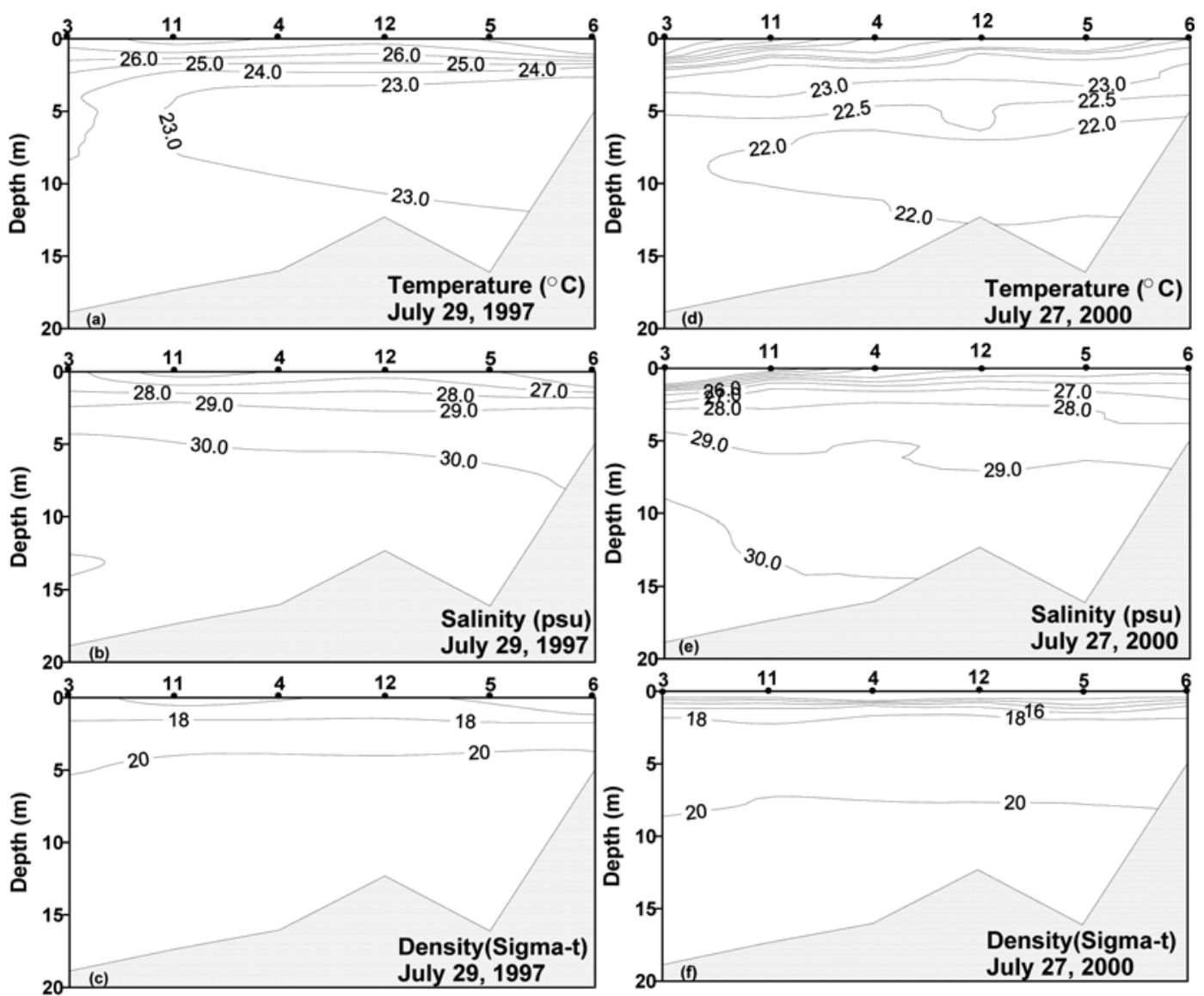

Fig. 3. Vertical water temperature, salinity, and density distribution for 29 July 1997 (a-c) and 27 July 2000 (d-f).

between approximately 29.5 and 30.5 psu, was observed in the middle layer in a tongue shape during July 1997. The temperature and salinity of the bottom water were about $24.0^{\circ} \mathrm{C}$ and $30.5 \mathrm{psu}$, respectively. The temperature in the middle layer was $22.0^{\circ} \mathrm{C}$ in July 2000 , which is colder by $0.5^{\circ} \mathrm{C}$ than that found at the bottom. The salinity of the middle layer, 29.0 30.0 psu, was higher than the surface salinity but lower than the bottom salinity. Although there was a temperature minimum layer in the middle depth, the density and salinity increased monotonically from the surface to the bottom. The saline warm water at the bottom could have resulted from the inflow of saline water from the open sea, as in a normal estuary.

\section{Variability of the vertical temperature structure}

Long-term observational data were examined between 1997 and 2002 to analyze the annual variation in the vertical temperature structure of the YE. The temporal evolutions of temperature profiles during summer were compared from 1997 to 2002, as shown in Fig. 4. Interestingly, the multi-layered structure persisted for the entire summer of 2000 but appeared sparsely in the other years.

The fresh water from the YR is about $3^{\circ} \mathrm{C}$ warmer than the ambient water in the YE for summer. It is common for the surface fresh warm water structure to appear every summer. The fresh warm surface water produces strong stratification during summer. In autumn, the stratification is broken, with the surface mixed layer becoming deep due to surface cooling. However, in 2000, the surface warm water persisted longer than during the other years.

In Fig. 4, the solid lines above the panel represent the presence of the temperature minimum layer. The temperature minimum layer appeared sparsely between 1997 and 1999 . Although the temperature in the entire layer slowly increased with time, the temperature in the middle layer was maintained at the minimum for the entire summer of 2000. The temperature at the bottom increased faster than that of the middle layer, supporting the suggested explanation of warm water inflow from the sea along the bottom of the YE.

Cold water, less than $20^{\circ} \mathrm{C}$, lasted longer in the middle 

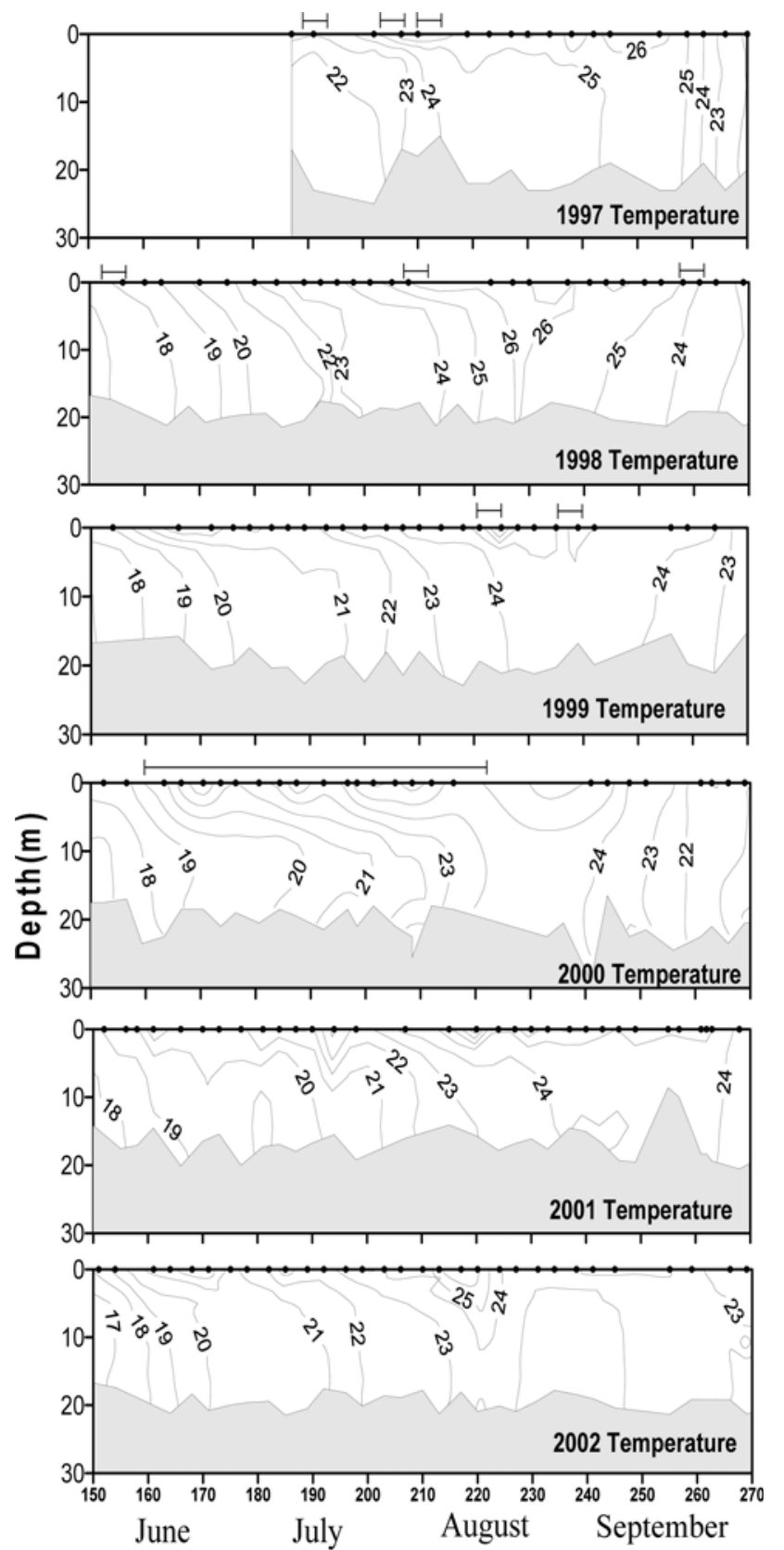

Julian Day

Fig. 4. The evolution of vertical water temperature profiles at station 2 during summer between 1997 and 2002. The stick bars above each panel represent the time when the temperature minimum layer appeared, and the dark circles denote the observation day.

layer during 2000 and 2001 than during the other years. This might be related to the temperature during the previous winter, as the water in the middle layer is isolated from the air by surface water during spring and summer. Air temperatures of the previous winters were lowest during 2000 and 2001 (Fig. 2).

\section{Discussion}

\section{Unique sea condition in 2000}

The temperature-salinity (T-S) diagrams shown in Fig. 5 were closely examined to understand the special distribution pattern of the mid-layer temperature minima in August 2000. Surface data measured at an open sea station $72 \mathrm{~km}$ west of the YE were added to the diagram (Fig. 5). Station 311-4 of the National Fisheries Research and Development Institute (www.nfrdi.re.kr) was selected. In general, temperatures decreased, whereas salinities increased, with depth. The temperature and salinity of the surface water showed large year-to-year variations. The major factor causing this large variation in the surface salinity is the fresh water discharge from the YR. The lower layer showed relatively small variation and was warmer in 1997 and 1998 and colder in 2000 and 2001, respectively. The year-to-year variation of the open sea had a different pattern from that of the YE.

The density difference between the open sea and the lower layer of the YE was large in 2000 and 2002. However, the open sea water was about $1{ }^{\circ} \mathrm{C}$ warmer in 2000 but about $3^{\circ} \mathrm{C}$ colder in 2002 than the lower layer water of the YE. The low temperature of the open sea water in 2002 might have been due to surface cooling by the low air temperature (Fig. 2).

The most critical factor determining the hydrography in the YE may be the amount of fresh water input from the river, as well as the input frequency.

The mean density difference between the open sea and the YE was large in August of 1998 and 2000 compared to other years (Fig. 2). The large horizontal density gradient might provide better conditions for driving warm saline seawater into the YE along its bottom, as will be discussed in the following section.

Another factor was the air temperature of the previous winter, which is essential to determining the water temperature. It is notable that the lowest air temperature in 2000 was recorded when the temperature minimum layer persisted for the entire summer (Fig. 2). However, winter temperatures were relatively high in 1997 and 2002, when the large horizontal density difference was comparable to that in 2000. The cold water formed during winter 2000 could have provided a good initial condition for keeping the intermediate layer relatively cold because it would have been isolated from the air by strong stratification during spring and summer. 

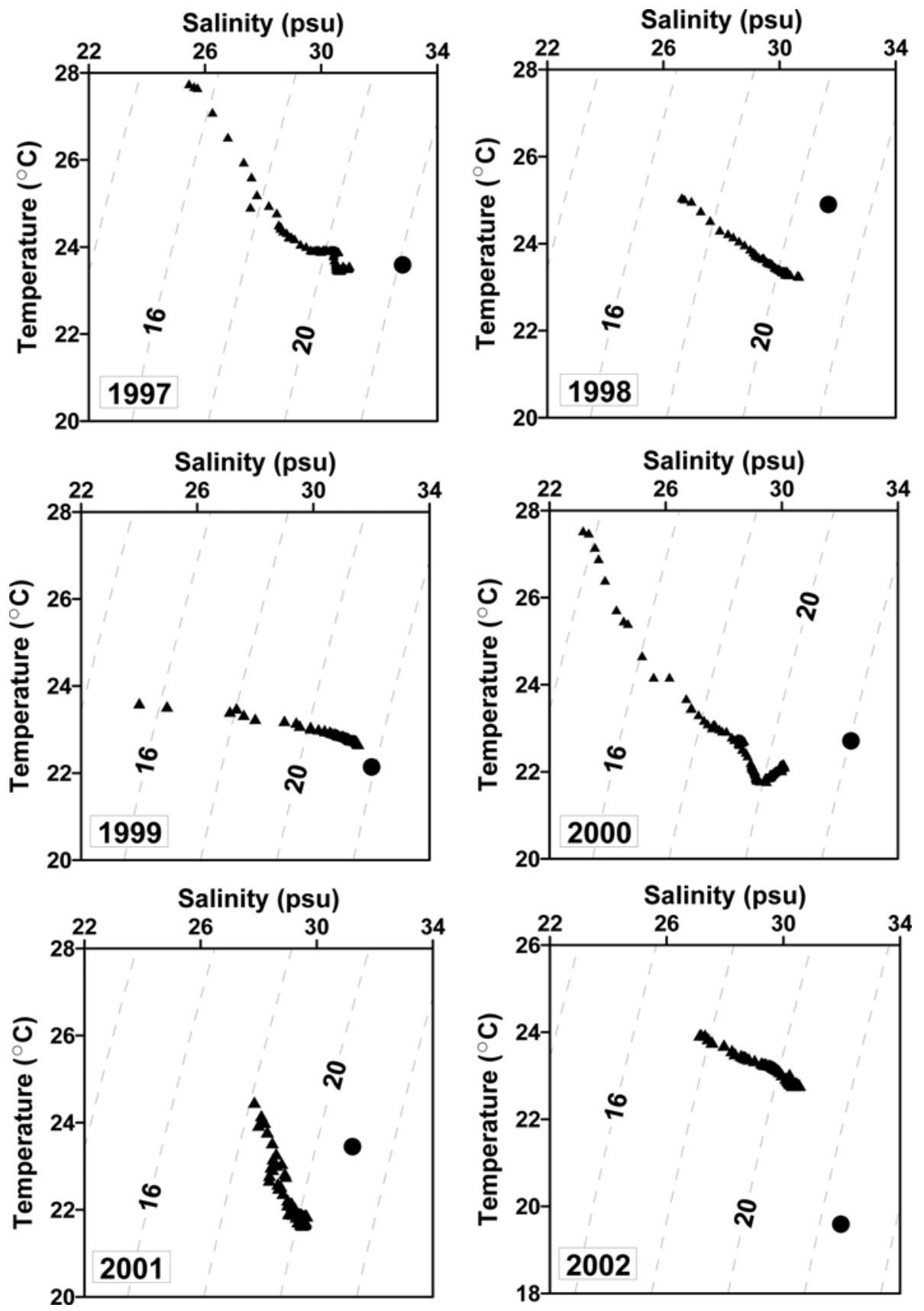

Fig. 5. Temperature-salinity diagrams of the Youngsan Estuary (station 2, triangles) and open sea (station 311-4 of NFRDI, circles) during August of each year of the study period. The observation days in the Youngsan Estuary were 29 July 1997, 27 July 1998, 29 July 1999 and 2000, and 26 July 2001 and 2002. The NFRDI data for August of each year were acquired on 15 August 1997, 18 August 1998, 14 August 1999, 14 August 2000, 8 August 2001, and 16 August 2002.

\section{Density-driven current}

The density difference between the open sea and the estuary might produce density-driven outflow in the surface layer and inflow in the bottom layer. To evaluate the density-driven current, the analytical solution of the Hansen-Rattray profile was adopted (Officer 1976).
The velocity along the channel at each depth is given by

$$
\begin{aligned}
& U(\xi)=\frac{g h^{3}}{48 N_{z} \rho}\left(\frac{\partial \rho}{\partial x}\right)\left(1-9 \xi^{2}+8 \xi^{3}\right)+\frac{1}{4} \frac{\tau_{w} h}{\rho N_{z}}\left(1-4 \xi+3 \xi^{2}\right) \\
& \xi=Z / h
\end{aligned}
$$


where $N_{z}$ is the eddy viscosity, $\rho$ is the water density, $h$ is the total depth from the surface to the bottom, $Z$ is the depth below the surface, $\tau_{w}$ is the wind stress, and $\mathrm{g}$ is gravity acceleration $\left(9.8 \mathrm{~m} / \mathrm{s}^{2}\right)$.

For an estimation of the density-driven current in the YE, the CTD data observed on 5 June 2003 were employed. The horizontal density gradient, $1 / \rho(\partial \rho / \partial x)$, between station 3 and station 5 was $1.23 \times 10^{-7} / \mathrm{m}$.

The following formula was used for the eddy viscosity, as proposed by Bowden (1953):

$$
\mathrm{N} z=3.3 \times 10^{-3} \mathrm{Uh}
$$

where $U$ is the tidal current amplitude. After the construction of the sea dike in the YE, the tidal current greatly decreased. The along-channel maximum tidal current speed of $10.0 \mathrm{~cm} / \mathrm{s}$ observed on 5 June 2003 in the YE and the along-channel daily mean wind stress of $22 \times 10^{-4}$ dyne $/ \mathrm{m}^{2}$ were used

Fig. 6 shows the calculated currents in relation to depth using the CTD and wind stress data measured on 5 June 2003. The two-layered flow was induced by the density structure in the YE and was seemingly consistent with the hydrographic structure.

To verify inflow from the open sea in the lower layer, the observed current in the YE was used. The axis was rotated to follow the estuary channel. The velocity data were converted on the sigma coordinate because of the large amplitude of tide. Tidal currents were removed by $36 \mathrm{~h}$ low-pass filtering. A positive velocity represents inflow to the estuary and negative velocity indicates

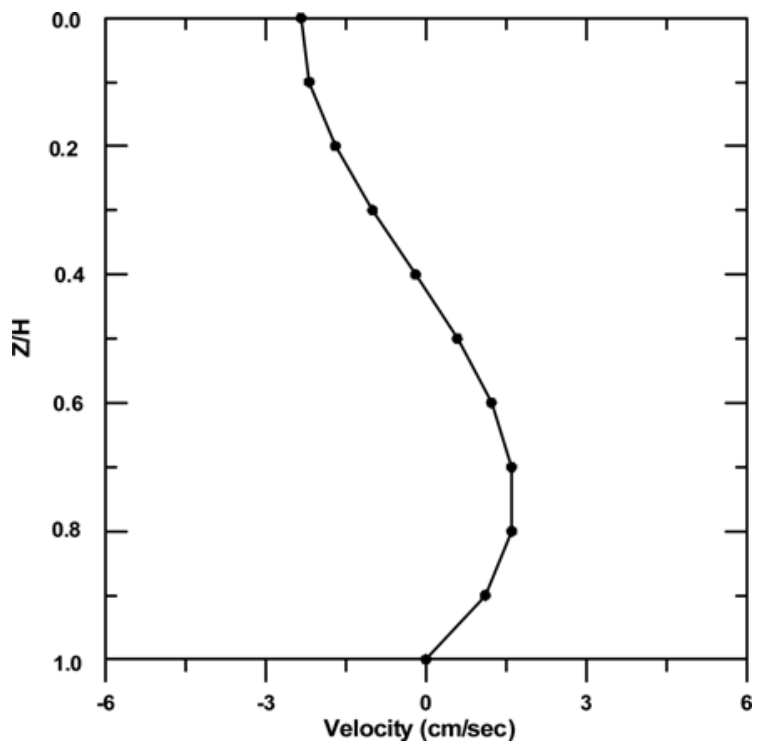

Fig. 6. Vertical profile of the density-driven current calculated from the density taken on 5 June 2003. outflow. The wind vector, fresh water discharge time series, and profiles of the filtered velocities on the sigma level are plotted in Fig. 7. The discharge volume ranged between 1.40 and $18.5 \times 10^{6} \mathrm{~m}^{3}$ for each discharge during the observation period. Sudden increases in the bottom water temperature were observed between 7 and 8 June, which could imply the inflow of warm water at the bottom into the YE, as the bottom water could not be heated from the surface due to insulation by the upper layer.

The surface velocity varied largely due to river discharge and wind, whereas the lower velocity flowed steadily. The surface layer had strong currents when discharge occurred. The mean flow during the observation period was mainly a typical two-layer circulation, with intrusion of bottom water from the open sea and seaward motion of the surface water, except in periods of river discharge. The measured velocity was comparable with those calculated at the surface and bottom, as shown in Fig. 6. The measured velocities at the subsurface and the bottom on 5 June 2003 when the wind was weak were $-2.0 \mathrm{~cm} / \mathrm{s}$ and $1.0 \mathrm{~cm} / \mathrm{s}$, respectively. These values are comparable to those calculated at the surface $(-2.2 \mathrm{~cm} / \mathrm{s})$ and the bottom

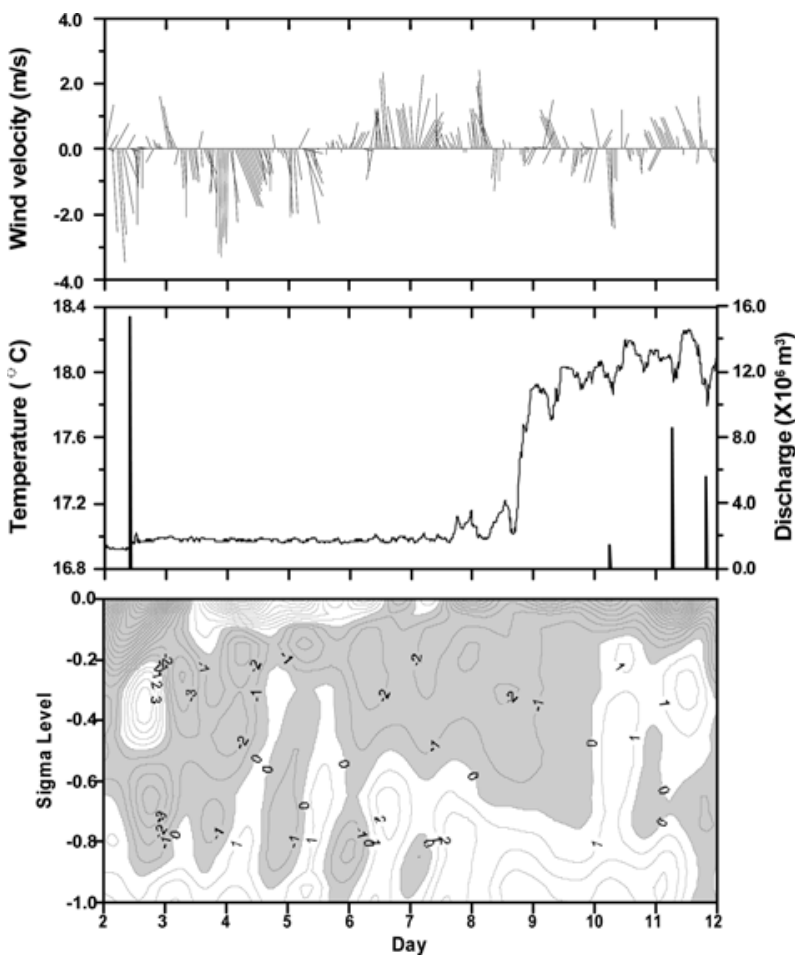

Fig. 7. Wind vectors (top panel), river discharge and bottom temperature (mid-panel), and $36 \mathrm{~h}$ filtered currents (bottom panel) between 2 and 12 June 2003. The contour interval for the current is $1 \mathrm{~cm}$ $\mathrm{s}^{-1}$. Gray shading represents outflow to the sea. 


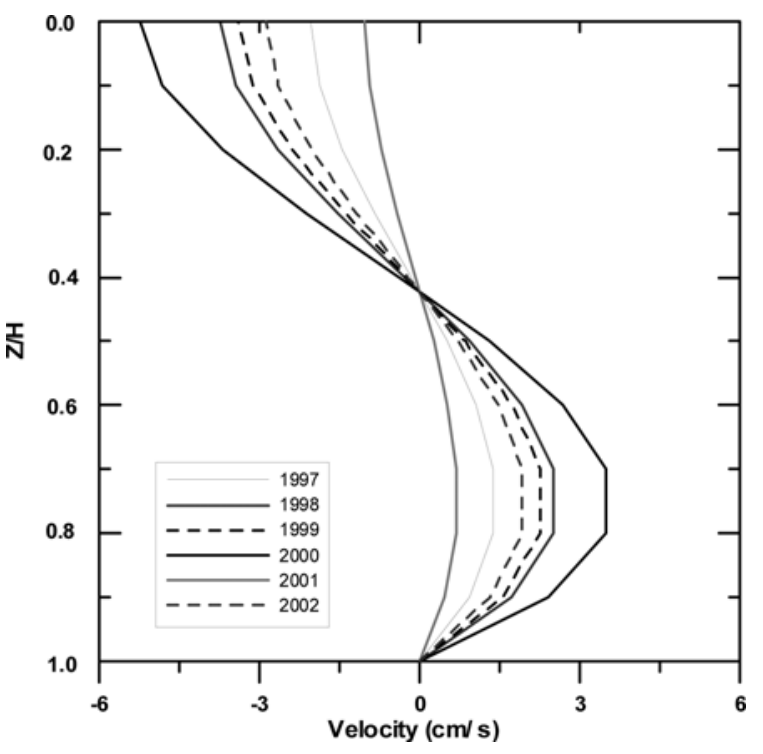

Fig. 8. Vertical profile of the density-driven current from 1997 to 2002, which was calculated from the averaged density difference in August between the open sea and Youngsan Estuary.

\section{$(1.2 \mathrm{~cm} / \mathrm{s})$, respectively.}

We compared the calculated vertical velocity profile based on observed density and mean wind stress in August of each year. Fig. 8 presents the density-driven current between the open sea and YE in August from 1997 to 2002. All profiles show surface outflow and bottom inflow as in a normal estuary. However, the speed of the current had large year-to-year variability. The speed was largest in 2000 and smallest in 2001. The large density-driven current in 2000 might have driven greater warm ocean water inflow than in other years.

\section{Calculated Richardson number}

Strong stratification might allow the multi-layered structure to remain stable. The bulk Richardson number $R_{i L}$ was calculated to examine the stability of the water column:

$$
R_{i L}=g h \frac{\Delta \rho}{\left(\rho U^{2}\right)}
$$

where $h$ is the water depth, $\Delta \rho$ is the density difference between the surface and bottom, and $U$ the depthaveraged velocity (Dyer and New 1986). Accordingly, if $R_{i L}$ is larger than 20 , the water column will be stable.

The Richardson number calculated from the mean density for the 3 months of June, July, and August varied from 52 to 207 (Table 1), with the highest value in 2000 . The density difference between the surface and bottom
Table 1. The $R i_{L}$ and differences in temperature, salinity, and density between the surface and bottom, averaged from June to August in each year

\begin{tabular}{|c|c|c|c|c|c|}
\hline Year & 1998 & 1999 & 2000 & 2001 & 2002 \\
\hline$R i_{L}$ & 91 & 113 & 207 & 52 & 60 \\
\hline Salinity difference (psu) & 6.3 & 7.9 & 13.3 & 4.0 & 4.1 \\
\hline Temperature difference $\left({ }^{\circ} \mathrm{C}\right)$ & 0.9 & 1.2 & 2.8 & 1.5 & 1.3 \\
\hline Density difference $\left(\mathrm{kg} / \mathrm{m}^{3}\right)$ & 5.0 & 6.3 & 10.9 & 3.4 & 3.4 \\
\hline
\end{tabular}

waters was about $11 \mathrm{~kg} / \mathrm{m}^{3}$. This large difference was mainly due to the low salinity of the surface as a result of the frequent discharges during 2000. The strong stability provided favorable conditions for persistence of the multilayered structure, regardless of the tidal cycle, throughout the entire summer of 2000.

\section{Conclusions}

Long-term observation revealed large year-to-year variability of the vertical temperature structure in the YE. The remarkable change in the vertical structure is caused by the multi-layered structure with a temperature minimum layer in the middle depth. The temperature minimum layer persisted for the entire summer during 2000, whereas it was only sparsely observed during the other study years.

The cold winter and the low density due to frequent discharges in the YE during the summer of 2000 might have been the major factors causing the unique structure in 2000. The cold winter probably enabled the middle layer to remain cold for longer and created a large temperature difference between the open sea and inner estuary. In addition, the large density difference between the open sea and the YE, mainly caused by the low salinity in the YE, might have more actively driven the inflow of warm sea water along the bottom to the YE during 2000.

The current calculated on the basis of the observed temperature and salinity suggests that the water in the lower layer inflows steadily due to the density difference. The current observed in the YE supports a bi-directional flow, with an inflow of warm sea water at the bottom and an outflow at the surface. The large Richardson number found during 2000 provided a good condition for the persistence of the multi-layered structure for the entire summer.

The cold winter, strong stratification, and large density difference between the open sea and the YE were major contributors to the formation of the unique multi-layered 
structure, with a temperature minimum layer and that was maintained during the entire summer of 2000 . However, more quantitative definitions for each factor involved in the formation of the multi-layered structure and its maintenance are required.

\section{Acknowledgements}

We are grateful to Dr. D.S. Byun, Cheol Cho, and Dr. Y.J. Sun for their support during the fieldwork and data analyses. This work was funded by the Korea Meteorological Administration Research and Development Program under grant CATER 2009-4506.

\section{References}

Bowden KF (1953) Note on wind drift in a channel in the presence of tidal currents. Proceedings of the Royal society of London, A219:426-446

Byun DS, Wang XH, Holloway PE (2004) Tidal characteristic adjustment due to dyke and seawall construction in the Mokpo coastal zone, Korea. Estuar Coast Shelf Sci 59: $185-196$

Cho YK, Park LH, Cho C, Lee IT, Park KY, Oh CW (2004) Multi-layer structure in the Youngsan Estuary, Korea. Estuar Coast Shelf Sci 61:325-329

Dyer KR, New AL (1986) Intermittency in estuarine mixing. In: Wolfe DA(ed) Estuarine Variability. Academic
Press, Orlando, pp 321-339

Kang JW (1999) Changes in tidal characteristics as a result of the construction of sea-dike/sea-walls in the Mokpo coastal zone. Estuar Coast Shelf Sci 48:429-438

Lee SW (1992) Korean nearshore oceanology. Jipmoondang, Seoul, $334 \mathrm{p}$

Lee SW (1994) Change in tidal height at Mokpo Harbor due to the construction of Youngsan River Estuary Dyke. Korean harbour hydraul 18:27-37

Lewis RE, Riddle AM, Lewis JO (1998) Effect of a tidal barrage on currents and density structure in Tees Estuary. In: Dronkers J, Scheffers M (eds) Physics of estuaries and coastal seas. Balkema, Roterdam, pp 33-38

Lim HS, Park KY (1998) Community Structure of the Macrobenthos in the Soft Bottom of Youngsan River Estuary, Korea, 1. Benthic Environment. J Korean Fish Soc 31(3):330-342

Lim HS, Park KY (1999) Community Structure of macrobenthos in the subtidal soft bottom in semi-enclosed Youngsan River Estuarine Bay, southwest coast of Korea. J Korean Fish Soc 32(3):320-332

Officer CB (1976) Physical Oceanography of Estuaries (and Associated Coastal Waters). Wiley, New York, 465 p

Rural Development Corporation of Korea (1999) Annual report of the management of the Estuary dike. Rural Development Corporation of Korea

Received Mar. 31, 2009 Revised May 6, 2009 Accepted Jul. 16, 2009 